\section{The Mathematics of Sustainability}

Assuring a sustainable future for our children and grandchildren is, arguably, the greatest challenge facing humanity and raises a plethora of scientific and mathematical challenges. In the language of the Brundtland Report World Commission on Environment and Development, 1987 , it means leaving for future generations the same options we have for how we want to live our lives. However, operationalizing that concept is easier said than done [Solow, 1991].

For energy sustainability alone, mathematics has much to contribute in finding better and less polluting ways to explore for new energy, in increasing combustion efficiency, in the development of alternative energy, in the management of energy grids and networks, and in minimizing the climate consequences of energy use. For sustainability of financial markets and economic systems, the role of mathematics is equally ubiquitous and essential. For the remainder of this article, however, I will focus on a less appreciated aspect: the services, direct and indirect, that ecosystems provide humanity [Daily, 1997], [Ehrlich and Mooney, 1983]. Sustaining these services-including food, fiber, fuel, pharmaceuticals, climate mediation, the sequestration of toxics, and simply aesthetics like the protection of charismatic species-may represent the most urgent challenge of all.

The protection of many ecosystem services is tied to protecting broad patterns of species abundance and nutrient cycling. These macroscopic features, while insensitive to much detail about particular organisms or species, obviously emerge from the collective properties of large numbers of interactions among individual organisms; and understanding how this occurs is at the core of protecting services. Similar issues relate to the governance of the biosphere, where the microscopic interactions are among people or governments pursuing their own selfish agendas, with macroscopic consequences that affect all. Evolution repeatedly has confronted this challenge at multiple levels, for example, in the emergence of multicellularity [Levin, 2010], and it is crucial for us to learn how to do so at the global level. Hence, initially, I identify a set of mathematical challenges towards achieving sustainability:

- Develop a statistical mechanics of ecological communities, socio-economic systems, and the biosphere.

- Model the emergence of an ecological pattern.

- Determine indicators of impending critical transitions between states.

DOI: http://dx.doi.org/10.1090/noti982
- Develop schemes for robust governance in these multiscale systems.

None of these is unexplored, and all are foci of much current activity. For example, there has been a great deal of work on collective motion in animal populations and on moving from Lagrangian models that describe the actions of individuals to Eulerian models that capture population statistics [Flierl, Grünbaum, Levin, and Olson, 1999]. The methods require writing equations of the form

$$
\begin{aligned}
& n(\mathbf{x}, \mathbf{v}, t+\delta t) \\
& =\int d \mathbf{x}^{\prime} d \mathbf{v}^{\prime} \mathcal{P}_{\delta \mathbf{X}}\left(\mathbf{x}-\mathbf{x}^{\prime}-\mathbf{v}^{\prime} \delta t ; \mathbf{x}^{\prime}, \mathbf{v}^{\prime}, t\right) \\
& \quad * \mathcal{P}_{\delta \mathbf{v}}\left(\mathbf{v}-\mathbf{v}^{\prime}-\mathbf{a} \delta t ; \mathbf{x}^{\prime}, \mathbf{v}^{\prime}, t\right) n\left(\mathbf{x}^{\prime}, \mathbf{v}^{\prime}, t\right)
\end{aligned}
$$

for the evolution of the spatial position/velocity densities and then using an appropriate closure scheme to derive a continuum description. An alternative approach [Kevrekidis, 2002], using microscopic simulators in the absence of knowledge of specific closure schemes, is an example of exciting new mathematical technique development. Collective motion also has much to teach us about collective action more generally, especially regarding group decision making, and new mathematical tools are proving useful there [Brams, 1978], [Couzin et al., 2011], [Saari, 2008a, 2008b].

Ecosystems, the biosphere, and the coupled humanenvironmental systems in which they are embedded are complex adaptive systems [Holland, 1995], [Levin, 2003], in which individual agents interact locally, producing emergent patterns that feed back to affect individual behaviors. In such systems, scaling from the microscopic to the macroscopic is essential for understanding the drivers of pattern, the potential for collapse or regime shift, and the conflicts that arise between the interests of individual agents (whether organisms or institutions or nations) and the collective good. Pattern formation in such systems has long been a topic of mathematical interest [Turing, 1952], but new challenges remain. So too has there been historical mathematical interest in critical transitions and regime shifts [Thom, 1969], albeit not without controversy; but attention to early warning indicators has received new attention recently [Lenton, Livina, Dakos, van Nes, and Scheffer, 2012], [Scheffer, 2009], [Scheffer et al., 2009], [Scheffer et al., 2012].

Although understanding the science of the emergence and robustness of ecological pattern is essential to developing sustainability, it is far from sufficient. The greatest challenge facing us is to achieve cooperation in dealing with problems of the Global Commons [Hardin, 1968], [Levin, 1999], [Skyrms, 1996], especially as regards public goods and common pool resources. This brings to the fore a different set of mathematical tools-control theory, game theory, voting theory, and mechanism 
design [Barrett, 2007], [Dixit, Levin, and Rubenstein, 2012], [Akcay, Meirowitz, Ramsay, and Levin, 2012], [Maskin, 2008], [Myerson, 2008], [Saari, 2008a, 2008b]for identifying under what conditions cooperation is possible and how best to achieve it.

The problems of achieving sustainability are urgent and huge and will require complementary inputs of diverse disciplines [Levin and Clark, 2010], [Rehmeyer, 2011]. Obviously mathematics has a great deal to contribute in addressing these problems; but it is equally certain, as has always been the case, that new mathematics will be stimulated by the energy and freshness that comes from new applications and new challenges. The discipline of mathematics has much to contribute, and much to gain, from engagement.

\section{References}

E. AkCAy, A. Meirowitz, K. Ramsay, and S. A. LeVin (2012), Evolution of cooperation and skew under imperfect information, Proc. Natl. Acad. Sci. USA.

S. BARRETT (2007), Why Cooperate: The Incentive to Supply Global Public Goods, Oxford, UK: Oxford University Press.

S. J. BRAms (1978), The Presidential Election Game, New Haven: Yale University Press.

I. D. Couzin, C. C. IoAnnou, G. Demirel, T. Gross, C. J. Torney, A. HARTNETT , and N. E. LEONARD (2011), Uninformed individuals promote democratic consensus in animal groups. Science 334(6062), 1578-1580. doi: 10.1126/science.1210280.

G. C. DAILY, ed. (1997), Nature's Services: Societal Dependence on Natural Ecosystems, Washington, DC: Island Press.

A. Dixit, S. A. Levin, and D. I. Rubenstein (2012), Reciprocal insurance among Kenyan pastoralists, Theoretical Ecology.

P. R. EHRLICH and H. A. MoONEY (1983), Extinction, substitution and ecosystem services, Bioscience,33, 248-254.

G. Flierl, D. GrünbAuM, S. LeVIn, and D. Olson (1999), From individuals to aggregations: The interplay between behavior and physics, Journal of Theoretical Biology 196, 397-454.

G. HARDIN (1968), The tragedy of the commons, Science 162, 12431248.

J. Holland, (1995), Hidden Order. How Adaptation Builds Complexity, Reading, MA: Addison Wesley.

I. G. KevreKidis, C. W. GeAR, J. M. HyMAN, P. G. KevreKidis, O. RuNBORG, and C. THEODOROPOULOS (2002), Equation-free multiscale computation: enabling microscopic simulators to perform system-level tasks, Commun. Math. Sci.

T. M. Lenton, V. N. LivinA, V. DAKos, E. H. VAN Nes, and M. SCHEFFER (2012), Early warning of climate tipping points from critical slowing down: comparing methods to improve robustness, Philosophical Transactions of the Royal Society A-Mathematical Physical and Engineering Sciences 370(1962), 1185-1204. doi: 10.1098/Rsta.2011.0304.

S. LEVIN (2010), Crossing scales, crossing disciplines: collective motion and collective action in the Global Commons, Philosophical Transactions of the Royal Society B-Biological Sciences 365(1537), 13-18. doi:10.1098/Rstb.2009.0197.

S. A. LeVIN (1999), Fragile Dominion: Complexity and the Commons, Reading, MA: Perseus Books.

(2003), Complex adaptive systems: Exploring the known, the unknown and the unknowable, Bulletin of the American Mathematical Society 40, 3-19.

S. A. LEVIN and W. C. CLARK, eds. (2010), Toward a Science of Sustainability: Report from the NSF toward a Science of Sustainability Conference, Warrenton, VA, November 29-December 2, 2009, Princeton, NJ: Princeton University Printing and Mailing Services.
E. S. MASKIN (2008), Mechanism design: How to implement social goals, American Economic Review 98(3), 567-576. doi: 10.1257/Aer.98.1.567.

R. B. MYERSON (2008), Perspectives on mechanism design in economic theory, American Economic Review 98(3), 586-603. doi:10.1257/Aer.98.3.586.

J. REHMEYER (2011), Mathematical and Statistical Challenges for Sustainability, Providence, RI: American Mathematical Society.

D. G. SAARI (2008a), Complexity and the geometry of voting. Mathematical and Computer Modelling 48(9-10), 1335-1356. doi:10.1016/J.Mcm.2008.05.033.

(2008b), Disposing dictators, demystifying voting paradoxes, Mathematical and Computer Modelling 48(9-10), 1671-1673. doi:10.1016/J.Mcm.2008.05.016.

M. SCHefFer (2009), Critical Transitions in Nature and Society, Princeton, NJ: Princeton University Press.

M. SChefFer, J. BASCOMPTE, W. A. BRocK, V. BRovkin, S. R. Carpenter, V. Dakos, and G. Sugihara (2009), Earlywarning signals for critical transitions, Nature 461(7260), 53-59. doi:10.1038/Nature08227.

M. Scheffer, S. R. CARpenter, T. M. Lenton, J. BAscompte, W. BROCK, V. DAKOS, and J. VANDERMEER (2012), Anticipating critical transitions, Science 338(6105), 344-348. doi: 10.1126/Science.1225244.

B. SKyrms (1996), Evolution of the Social Contract, New York: Cambridge University Press.

R. M. Solow (1991), Sustainability: An Economist's Perspective, Eighteenth J. Seward Johnson Lecture in Marine Policy, June 14, 1991, Woods Hole, Massachusetts: Woods Hole Oceanographic Institution, Marine Policy Center.

R. THOM (1969), Topological models in biology, Topology 8, 313335.

A. M. TuRING (1952), The chemical basis of morphogenesis, Philosophical Transactions of the Royal Society, Series B, 237, 37-72. WORLD COMMISSION ON ENVIRONMENT AND DEVELOPMENT (1987), Our Common Future, New York: Oxford University Press.

-Simon Levin Princeton University slevin@princeton.edu. 